\title{
DEMOGRAPHIC AND EPIDEMIOLOGICAL PROFILE IN ENT AND HEAD AND NECK CANCER PATIENTS
}

\author{
Surajeet Basumatari ${ }^{1}$, Balmiki Datta ${ }^{2}$, Ashok Jyoti Deka ${ }^{3}$
}

${ }_{1}^{1}$ Associate Professor, Department of ENT, FAAMCH, Barpeta, Assam.

${ }^{2}$ Associate Professor, Department of Pathology, FAAMCH, Barpeta, Assam.

${ }^{3}$ Assistant Professor, Department of Community Medicine, FAAMCH, Barpeta, Assam.

\section{BACKGROUND}

ABSTRACT

Head and Neck cancer (HNC) comprises a diverse group of oncological entities, originating from various tissue types and organ localisations all situated in the topographical region of the head and neck (H\&N). In India, the disproportionately higher incidence of HNC may be due to excessive consumption of tobacco in various forms with and without alcohol, low socioeconomic status leading to poor oral and dental hygiene, poor diet, and infections of viral origin.

The aim of the study is to analyse the demographic and epidemiological profile of the patients of head and neck carcinoma in terms of age, sex, socioeconomic status, site involved, smoking, alcohol and chewing habits, and histopathological diagnosis.

\section{MATERIALS AND METHODS}

This is a Hospital-based cross-sectional study conducted from January 2016 to September 2017 in Fakhruddin Ali Ahmed Medical College and Hospital, Barpeta in collaboration with Dept. of ENT and Dept. of pathology. It comprises of patients with suspected malignancy of ENT- Head and neck region confirmed by histopathological examination or Fine needle aspiration cytology or radiological investigation like CT scan. All the chosen cases of malignancy of ENT- Head and neck region were analysed for demographic and epidemiological profile.

\section{RESULTS}

Our study concluded that larynx was the most common site of malignancy (26.67\%). The mean age was $64.87 \pm 5.7$ years. Males were most commonly involved. Male to female ratio was 2.21:1. Squamous cell carcinoma was the most common histopathological type (87.78\%). Smoking and chewing was the most common behavioural risk factor associated with ENT, head and neck malignancy.

\section{CONCLUSION}

HNCs are one of the most common malignancies prevalent in India with wide variations in risk factors, sites of involvement, geographical, and demographic characteristics Consumption of tobacco in various forms along with smoking constitutes an important risk factor in causation of head and neck malignancy.

\section{KEYWORDS}

Head and Neck Malignancy, Squamous Cell Carcinoma, Tobacco.

HOW TO CITE THIS ARTICLE: Basumatari S, Datta B, Deka AJ. Demographic and epidemiological profile in ENT and Head and Neck cancer patients. J. Evolution Med. Dent. Sci. 2017;6(91):6417-6421, DOI: 10.14260/jemds/2017/1396

\section{BACKGROUND}

Head and neck cancer (HNC) comprises a diverse group of oncological entities, originating from various tissue types and organ localisations all situated in the topographical region of the head and neck $(\mathrm{H} \& \mathrm{~N}) .1,2$ The reported worldwide incidence of ENT and HNC is approximately 3\% of all cancer cases, with males being affected in nearly $90 \%$ of all cases and epithelial neoplasms representing more than $85 \%$ of all cancer types. $2,3,4,5$ Head and neck cancers (HNCs) are a major form of cancers in India, accounting for $23 \%$ of all cancers in males and $6 \%$ in females. In India, the disproportionately higher incidence of HNC compared to other common malignancies may be due to excessive consumption of tobacco

'Financial or Other Competing Interest': None.

Submission 27-09-2017, Peer Review 11-11-2017,

Acceptance 18-11-2017, Published 27-11-2017.

Corresponding Author:

Dr. Surajeet Basumatari,

Associate Professor,

Department of ENT,

FAAMCH, Barpeta, Assam.

E-mail: surajeetbasu.sb@gmail.com

DOI: $10.14260 /$ jemds $/ 2017 / 1396$ in various forms with and without alcohol, low socioeconomic status leading to poor oral and dental hygiene, poor diet, and infections of viral origin.

The prevalence of cancer is often strikingly dissimilar in different groups of population, varies greatly from one community to another, and differs in different communities in the same geographic location, depending on the practices and lifestyles of the people in that location. Moreover, differences have been observed in the aetiological, clinicopathological, and molecular pathological profile in the tobacco smoking, chewing, and alcohol associated oral cancers, particularly in the Indian subcontinent. ${ }^{6}$

\section{Aim of the study-}

To analyse the demographic and epidemiological profile of the patients of head and neck carcinoma in terms of age, sex, educational qualification, socioeconomic status, site involved, smoking, alcohol and chewing habits, and other clinical details and histopathological diagnosis.

\section{MATERIALS AND METHODS Type of Study}

Hospital-based cross-sectional study. 


\section{Place of Study}

Fakhruddin Ali Ahmed Medical College and Hospital (FAAMCH), Barpeta, Assam in collaboration with Dept. of ENT and Dept. of Pathology.

\section{Duration of Study}

January 2016- September 2017.

\section{Inclusion Criteria}

The study comprises of all the outpatient department and in patients attending FAAMCH, Barpeta with suspected malignancy of ENT- Head and neck region confirmed by histopathological examination or Fine needle aspiration cytology or radiological investigation like CT scan. All the chosen cases of malignancy of ENT, Head and neck region were analysed on the basis of age, sex, educational qualification, socioeconomic status, site involved, smoking, alcohol and chewing habits, and other clinical details and histopathological type.

\section{Exclusion Criteria}

All the HPE diagnosed cases of recurrence or on treatment in the form of surgery (came for review) or radiotherapy or chemotherapy were excluded from study.

\section{Methodology}

All the patients attending the OPD of Dept. of ENT or patients admitted in the ward of ENT or other departments presenting with complaints of hoarseness, foreign body sensation in throat, stickiness of throat, difficulty in swallowing, painful swallowing, suspicious neck gland or salivary gland which are hard to firm, nontender were suspected of oral, pharyngeal, laryngeal, salivary gland or oesophageal carcinoma. These patients underwent thorough evaluation of oral cavity, pharynx, larynx by indirect laryngoscopy or sometimes $70^{\circ}$ laryngoscopy and upper GI endoscopy. If any growth was seen, punch biopsy was taken from the growth. If the growth was in laryngopharynx, direct laryngoscopy was done and punch biopsy was taken. If upper GI endoscopy revealed oesophageal growth, the biopsy specimen was taken at the same sitting. Similarly, if the patient presented with epistaxis, nasal mass, swelling over cheek suspicious of sinonasal mass, then the patients underwent diagnostic nasal endoscopy and subsequently biopsy was taken. All the biopsy specimens were evaluated for histopathological examination in the Dept. of Pathology, FAAMCH, Barpeta. Any mass in the head and neck region including salivary gland swelling and thyroid swelling underwent fine needle aspiration cytology (FNAC) and ultrasonography to ascertain the histology of the swelling. Few cases underwent radiological investigation like CT scan.

Based on the reports of histopathological examination of punch biopsy specimen, FNAC of the swelling in the head and neck region and radiological investigation i.e. CT scan in few cases, demographic and epidemiological profile of the patients of head and neck carcinoma were analysed in terms of age, sex, site of carcinoma, education, socioeconomic status, histological type of carcinoma, associated metastasis and any other predisposing factors like chewing tobacco, betel nut, alcohol, radiation exposure, etc.

\section{RESULTS}

This hospital-based cross-sectional study was conducted in collaboration with Department of ENT and Pathology, FAAMCH, Barpeta from January 2016 to September 2017 in 90 patients after fulfilling inclusion and exclusion criteria. During the study period, 122 cases with suspected malignancy of ENT, Head and Neck region were chosen out of which 31 cases were of laryngeal growth, 24 cases were of suspected oesophageal growth, 22 cases of hypopharyngeal growth, 12 cases of salivary gland swelling, 10 cases were of tonsillar growth, 9 cases of oral cavity growth, 8 cases of sinonasal mass, 6 cases of lip growth, 7 cases of base of tongue and 5 cases of thyroid malignancy. All the cases were subjected to punch biopsy except 5 cases of suspected thyroid malignancy, 12 cases of salivary gland swelling. Concomitantly investigations like FNAC, ultrasonography and CT scan were advised results of which were evaluated and discussed below.

However, 90 patients were included in the study as 90 cases were reported as malignant growth after evaluating histopathological examination report, FNAC, ultrasonography and CT scan results.

\begin{tabular}{|c|c|}
\hline Site of Malignancy & Mean Age in Years \\
\hline Laryngeal carcinoma & $68.4 \pm 9.2$ \\
\hline Pharyngeal carcinoma & $64.67 \pm 10.3$ \\
\hline Oesophageal carcinoma & $70.43 \pm 8.9$ \\
\hline Tonsillar carcinoma & $61.2 \pm 3.8$ \\
\hline Salivary gland carcinoma & $67.63 \pm 8.56$ \\
\hline Oral cavity carcinoma & $60.23 \pm 6.8$ \\
\hline Sinonasal malignancy & $54.67 \pm 10.2$ \\
\hline Lip carcinoma & $63.67 \pm 8.67$ \\
\hline Base of tongue & $59.67 \pm 8.90$ \\
\hline Thyroid carcinoma & $30.56 \pm 4.6$ \\
\hline \multicolumn{2}{|c|}{ Table 1. Age Distribution of the Patients } \\
\hline
\end{tabular}

Mean age of the patients diagnosed as malignancy has been described in the above table according to the site of malignancy.

\begin{tabular}{|c|c|c|}
\hline Site & No. of patients(90) & \% of Patients \\
\hline Larynx & 24 & 26.67 \\
\hline Pharynx & 20 & 22.22 \\
\hline Oesophagus & 14 & 15.56 \\
\hline Oral cavity & 7 & 7.78 \\
\hline Tonsil & 8 & 8.89 \\
\hline Lip & 4 & 4.44 \\
\hline Salivary gland & 2 & 2.22 \\
\hline $\begin{array}{c}\text { Nose and paranasal } \\
\text { sinus }\end{array}$ & 3 & 3.33 \\
\hline Base of tongue & 6 & 6.66 \\
\hline Thyroid & 2 & 2.22 \\
\hline
\end{tabular}

In the above table, we can observe that out of 90 patients laryngeal carcinoma comprises of $26.67 \%$ cases which is the most common type in our study followed by pharyngeal carcinoma (22.22\%), oesophageal carcinoma (15.56\%), carcinoma tonsil $(8.89 \%)$, oral cavity carcinoma $(7.78 \%)$, base of tongue carcinoma (6.66\%), sinonasal malignancy $(3.33 \%)$ and salivary gland malignancy $(2.22 \%)$ and thyroid carcinoma $(2.22 \%)$. 


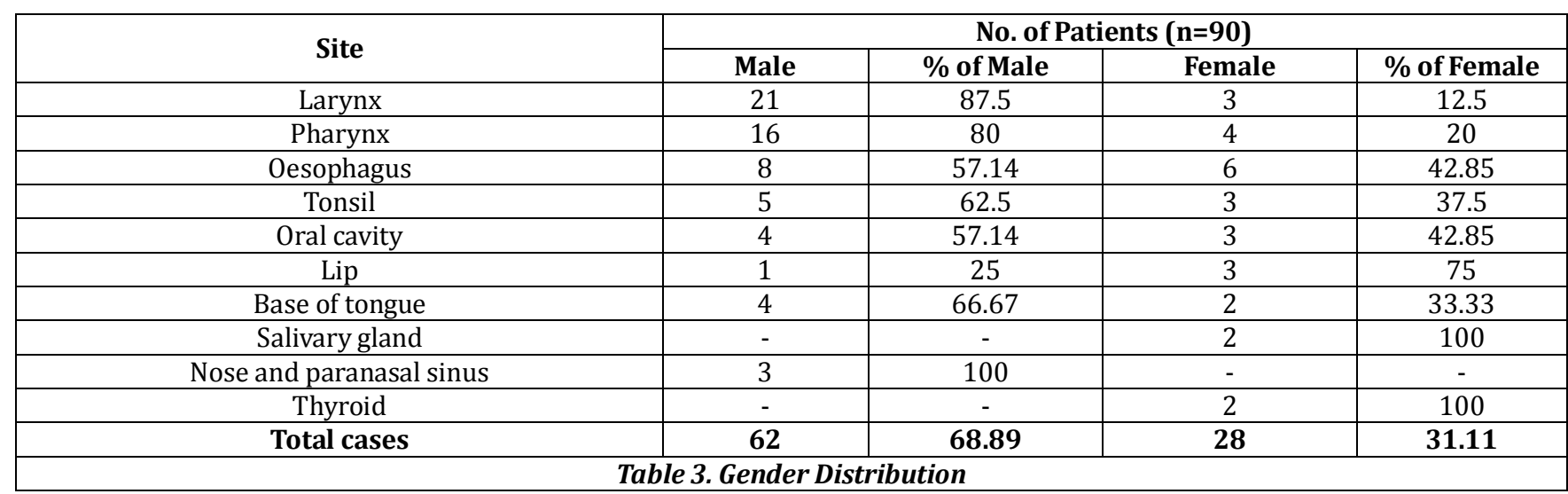

The above table shows the gender distribution of head and neck carcinoma according to the site. It has been seen that males are predominantly involved. Out of 90 patients, 62 i.e. $68.89 \%$ patients were male while 28 cases i.e. $31.11 \%$ cases were female. Overall, male to female ratio is $2.21: 1$.

\begin{tabular}{|c|c|c|c|c|c|c|c|c|}
\hline \multirow{2}{*}{ Site } & \multicolumn{6}{|c|}{ HPE } & \multirow[t]{2}{*}{ FNAC } & \multirow[t]{2}{*}{ Total cases } \\
\hline & SCC & AC & Lymphoma & Papillary & Follicular & others & & \\
\hline Larynx & 24 & & & & & & & 24 \\
\hline Pharynx & 18 & 2 & & & & & & 18 \\
\hline Oesophagus & 11 & 5 & & & & & & 16 \\
\hline Tonsil & 6 & & 2 & & & & & 8 \\
\hline Oral cavity & 7 & & & & & & & 7 \\
\hline Lip & 4 & & & & & & & 4 \\
\hline Base of tongue & 6 & & & & & & & 6 \\
\hline Salivary gland & & & & & & & $\begin{array}{c}1(\mathrm{scc}) \\
1 \text { (lymphoma) }\end{array}$ & 2 \\
\hline Nose and paranasal sinus & 2 & 1 & & & & & & 3 \\
\hline Thyroid & & & & 1 & 1 & & $\begin{array}{l}\text { 1(papillary) } \\
1 \text { (follicular) }\end{array}$ & 2 \\
\hline
\end{tabular}

SCC- Squamous cell carcinoma, AC- Adenocarcinoma.

The above table shows histopathological distribution of head and neck carcinoma. The table reveals that squamous cell carcinoma is the most common type of malignancy followed by adenocarcinoma, lymphoma. Thyroid carcinomas were of papillary and follicular variants.

Histopathological diagnosis of salivary gland tumour and thyroid swelling has been established on the basis of FNAC.

Ultrasonography of salivary gland and thyroid swelling were done along with CT scan to confirm the diagnosis of malignancy along with FNAC report.

31 cases presented with neck swelling suspected of metastatic gland which were firm to hard in consistency and nontender. Two cases were infested with maggots with secondary infection in the neck gland. All the cases were subjected to FNAC of the neck swelling which revealed metastatic squamous cell carcinoma.

\begin{tabular}{|c|c|c|}
\hline Socioeconomic Status & No. of Cases & \% of Cases \\
\hline Class I (Rs. $\geq 5522$ ) & 9 & 10 \\
\hline Class II ( Rs. 2761-5521) & 15 & 16.67 \\
\hline Class III (Rs. 1657-2760) & 24 & 26.67 \\
\hline Class IV (Rs. 828-1656) & 38 & 42.22 \\
\hline Class V (< Rs. 828) & 6 & 6.67 \\
\hline
\end{tabular}

In our study, socioeconomic status was based on Modified BG Prasad Socioeconomic classification.7 The study reveals that $42.22 \%$ patients belong to class IV followed by class III (26.67\%), class II (16.67\%) class I (10\%) and class V (6.67\%) respectively.

\begin{tabular}{|c|c|c|}
\hline Risk Factors & No. of Patients & \% of Patients \\
\hline Only smoking & 6 & 6.67 \\
\hline Only alcohol & 4 & 4.44 \\
\hline Only chewing & 22 & 24.4 \\
\hline Smoking + alcohol & 11 & 12.22 \\
\hline Smoking + chewing & 29 & 32.22 \\
\hline Alcohol + chewing & 5 & 5.55 \\
\hline $\begin{array}{c}\text { Smoking + alcohol + } \\
\text { chewing }\end{array}$ & 13 & 14.4 \\
\hline $\begin{array}{c}\text { Exposure to } \\
\text { radiation }\end{array}$ & - & \\
\hline \multicolumn{2}{|c|}{ Table 6. Association of Risk Factors } \\
\hline \multicolumn{2}{|c|}{}
\end{tabular}

The above table shows that behavioural habits like smoking, alcohol, chewing betel nut, tobacco, etc. alone or in combination with each other is intricately associated with malignancy of different sites of ENT and head and neck region. Smoking and chewing is the most common behavioural risk factor. Consumption of alcohol is relatively less in this region because of cultural factors among Muslim population. 


\section{DISCUSSION}

This hospital-based cross-sectional study was conducted from January 2016 to September 2017 at Fakhruddin Ali Ahmed Medical College and Hospital, Barpeta, Assam in collaboration with Dept. of ENT and Dept. of Pathology after fulfilling inclusion and exclusion criteria in 122 cases. However, 90 patients were analysed in the present study as only 90 patients reviewed with investigation reports with diagnosis as malignancy of different sites of ENT and Head and Neck region.

In our study, mean age of the cases has been calculated according to the site of malignancy. The mean age of laryngeal carcinoma was $68.4 \pm 9.2$ years. George S Stoyanov et al found the mean age in laryngeal carcinoma to be $63.48 \pm 10.14$ years. Similarly, the mean age of pharyngeal $\mathrm{Ca}$, oesophageal $\mathrm{Ca}$, oral cavity $\mathrm{Ca}$, tonsillar $\mathrm{Ca}$, carcinoma base of tongue, $\mathrm{Ca}$ lip, Ca salivary gland, sinonasal malignancy and thyroid carcinoma are $64.67 \pm 10.3$ years, $70.43 \pm 8.9$ years, $60.23 \pm$ 6.8 years, $61.2 \pm 3.8$ years, $59.67 \pm 8.90$ years, $63.67 \pm 8.67$ years, $67.63 \pm 8.56$ years, $54.67 \pm 10.2$ years and $30.56 \pm 4.6$ years respectively. Similarly, the study by George S Stoyanov et al found the mean age of pharyngeal $\mathrm{Ca}$, oral cavity and lip $\mathrm{Ca}$, Ca salivary gland, sinonasal malignancy to be $61.92 \pm$ 12.94 years, $63.67 \pm 12.9$ years, $68.19 \pm 12.68$ years, $67.76 \pm$ 16.04 years respectively.

Our study concluded that larynx was the most common site of malignancy $(26.67 \%)$ study followed by pharyngeal carcinoma (22.22\%), oesophageal carcinoma (15.56\%), carcinoma tonsil $(8.89 \%)$, oral cavity carcinoma $(7.78 \%)$, base of tongue carcinoma (6.66\%), sinonasal malignancy $(3.33 \%)$ and Salivary gland malignancy $(2.22 \%)$ and thyroid carcinoma $(2.22 \%)$.

However, the study by George S Stoyanov et al found that the primary localisation site included the larynx $30.37 \%(\mathrm{n}=$ 188 ) cases, lips and oral cavity $29.08 \%(n=180)$, pharynx $20.03 \%(n=124)$, salivary glands $10.94 \%(n=68)$, external nose and nasal cavity $4.69 \%(\mathrm{n}=29)$, auricle and external ear canal $2.75 \%(n=17)$ and sinuses $2.1 \%(n=13){ }^{3}$

Mohammad Shadab Alam et al in their study found that the most common site of HNC was oral cavity followed by oropharynx and larynx. Malignancy arising from hypopharynx, nose and paranasal sinuses (PNS), and nasopharynx were uncommon. Secondary neck with unknown primary constituted 5\% of all HNC. Tumours arising from salivary glands, thyroid, external auditory canal, ear pinna, and eyelid all together account for $<2 \%$ of HNC. Most common subsite of HNC was base of tongue (BOT) (16\%) followed by buccal mucosa (14.2\%). Oral tongue $(13.5 \%)$ and supraglottic larynx (13.5\%) had equal incidence. ${ }^{8}$

Out of 90 patients, 62 i.e. $68.89 \%$ patients were male while 28 cases i.e. $31.11 \%$ cases were female. Male to female ratio is 2.21: 1 . Male to female ratio of the registered HNC cases was 3.24:1 in the study conducted by George S Stoyanov et al. ${ }^{3}$ However, the study conducted by Mohammad Shadab Alam et al found the male to female ratio to be $16: 1{ }^{8}$

Our study concluded that squamous cell carcinoma is the most common histological type of carcinoma (87.78\%). This is followed by adenocarcinoma and lymphoma. The main histopathological groups include squamous cell carcinoma $76.74 \%$ and adenocarcinoma $6.14 \%$ in the study conducted by George S Stoyanov et al. ${ }^{3}$ Similarly, the study conducted by
Mohammad Shadab Alam et al found squamous cell carcinoma to be the most common Head and Neck carcinoma (97\% cases). ${ }^{8}$

While analysing the risk factors associated with Head and Neck carcinoma, we found that smoking and chewing together was the most common behavioural risk factor.

In India, tobacco consumption is responsible for half of all the cancers in men and a quarter of all cancers in women. ${ }^{9}$ Variations in the incidence of HNC by site are mostly related to the relative distribution of major risk factors such as tobacco or betel-quid chewing, cigarette or bidi smoking, alcohol consumption, and viral infections. Smoking is relatively a more pronounced factor for cancer of pharynx (relative risk $[R R]=8.5)$ and larynx $(R R=7.5)$ than cancer of oral cavity $(\mathrm{RR}=4.9) \cdot{ }^{10}$ In the study by Mohammad Shadab Alam et $a l, 8$ smoking was present in $>80 \%$ cases of cancer of oropharynx, larynx, and hypopharynx and only $50 \%$ cases of oral cancer. There is a 6-fold higher risk of oral cancer among the people having habit of betel nut and tobacco (gutkha). ${ }^{11}$ In the study by Mohammad Shadab Alam et al, tobacco chewing including betel nut was present in $>60 \%$ cases of oral cancer and only $30 \%$ of pharynx and larynx cancer.

High alcohol consumption has RR $>5$ mainly for oral cavity, oropharynx, and oesophagus. When tobacco smoking and alcohol consumption are combined, they may increase the risk by more than 15 -fold. 12 This effect is possibly because alcohol may act as a solvent and enhance the penetration of carcinogens into target tissues. ${ }^{8}$

\section{CONCLUSION}

HNCs are one of the most common malignancies prevalent in India with wide variations in risk factors, sites of involvement, geographical, and demographic characteristics. Head and Neck cancers (HNCs) are the sixth most common malignancy and are a major cause of cancer morbidity and mortality worldwide. Larynx is the most commonly involved site in Head and Neck carcinoma in this study and squamous cell carcinoma being the most common histological type commonly involving the male population. Consumption of tobacco in various forms along with smoking constitutes an important risk factor in causation of head and neck malignancy. However, more detailed study comprising of greater number of cases for longer duration along with special emphasis on molecular or genetic level is required to form definite conclusion regarding different factors associated with ENT and Head and Neck carcinoma.

\section{REFERENCES}

[1] Argiris A, Karamouzis MV, Raben D, et al. Head and neck cancer. Lancet 2008;371(9625):1695-709.

[2] Sturgis EM, Wei Q Spitz MR. Descriptive epidemiology and risk factors for head and neck cancer. Semin Oncol 2004;31(6):726-33.

[3] Stoyanov GS, Kitanova M, Dzhenkov DL, et al. Demographics of head and neck cancer patients: a single institution experience. Cureus 2017;9(7):e1418.

[4] Davies L, Welch HG. Epidemiology of head and neck cancer in the United States. Otolaryngol Head Neck Surg 2006;135(3):451-7.

[5] Mehanna H, Paleri V, West CM, et al. Head and neck cancer--part 1: epidemiology, presentation, and prevention. BMJ 2010;341:c4684. 
[6] Addala L, Pentapati CK, Reddy Thavanati PK, et al. Risk factor profiles of head and neck cancer patients of Andhra Pradesh, India. Indian J Cancer 2012;49(2):215-9.

[7] Mangal A, Kumar V, Panesar S, et al. Updated BG Prasad socioeconomic classification, 2014: a commentary. Indian J of Public Health 2015;59(1): 42-4.

[8] Alam MS, Siddiqui SA, Perween R. Epidemiological profile of head and neck cancer patients in western Uttar Pradesh and analysis of distributions of risk factors in relation to site of tumor. J Cancer Res Ther 2017;13(3):430-5.

[9] WHO. Tobacco or Health: A Global Status Report. Geneva: World Health Organization; 1997.
[10] Lewin F, Norell SE, Johansson H, et al. Smoking tobacco, oral snuff, and alcohol in the etiology of squamous cell carcinoma of the head and neck: a population-based case-referent study in Sweden. Cancer 1998;82(7):1367-75.

[11] Jayant K, Balakrishnan V, Sanghvi LD, et al. Quantification of the role of smoking and chewing tobacco in oral, pharyngeal, and oesophageal cancers. Br J Cancer 1977;35(2):232-5.

[12] Tuyns AJ, Estève J, Raymond L, et al. Cancer of the larynx/hypopharynx, tobacco and alcohol: IARC international case-control study in Turin and Varese (Italy), Zaragoza and Navarra (Spain), Geneva (Switzerland) and Calvados (France). Int J Cancer 1988;41(4):483-91. 